\title{
Radiotherapy tumor volume for limited-stage small cell lung cancer: less is more
}

\author{
Antonin Levy ${ }^{1,2,3}$, Corinne Faivre-Finn ${ }^{4,5}$ \\ ${ }^{1}$ Department of Radiation Oncology, Institut d'Oncologie Thoracique (IOT), Gustave Roussy, Villejuif, France; ${ }^{2}$ Univ Paris Sud, Université Paris- \\ Saclay, Le Kremlin-Bicêtre, France; ${ }^{3}$ INSERM U1030, Molecular Radiotherapy, Gustave Roussy, Université Paris-Saclay, Villejuif, France; ${ }^{4}$ Division \\ of Cancer Sciences, Faculty of Biology, Medicine and Health, The University of Manchester, The Christie NHS Foundation Trust, Manchester, UK; \\ ${ }^{5}$ The Christie NHS Foundation Trust, Manchester, UK \\ Correspondence to: Antonin Levy, MD, PhD. Department of Radiation Oncology, Gustave Roussy, Université Paris-Saclay, F-94805, Villejuif, France. \\ Email: Antonin.LEVY@gustaveroussy.fr. \\ Provenance and Peer Review: This article was commissioned and reviewed by the Section Editor Dr. Chun-Ru Chien (Director, Department of \\ Radiation Oncology, China Medical University Hsinchu Hospital, Hsinchu; Professor, Department of Radiation Oncology, China Medical \\ University, Taichung). \\ Comment on: Hu X, Bao Y, Xu Y, et al. Final report of a prospective randomized study on thoracic radiotherapy target volume for limited-stage small \\ cell lung cancer with radiation dosimetric analyses. Cancer 2020;126:840-9.
}

Submitted Mar 19, 2020. Accepted for publication Apr 01, 2020.

doi: $10.21037 /$ atm.2020.04.45

View this article at: http://dx.doi.org/10.21037/atm.2020.04.45

For the last 30 years, radiation therapy (RT) has been part of the standard treatment for limited-stage small cell lung cancer (LS-SCLC or stage I-III according to the TNM classification) $(1,2)$. With advances in radiation techniques, questions were raised about the optimal RT treatment volumes, in addition to questions relating to the fractionation and timing of RT with chemotherapy $(3,4)$. Historically, treatment volumes included all gross disease present at the time of initial diagnosis (prechemotherapy volume), as well as inclusion of adjacent uninvolved nodal regions (elective node irradiation: ENI). The available literature on volume reduction strategies is much more limited in SCLC compared to non-small cell lung cancer (NSCLC) but several reports $(5,6)$, including two randomized trials, assessed RT target volumes in LSSCLC (7-9).

The first question on RT target volume in LS-SCLC is related to the need to include ENI. In a phase II study including the pre-chemotherapy primary tumour and nodal volumes defined on CT scan (no ENI), De Ruysscher et al. reported an isolated nodal failure in $3 / 27$ (crude rate of $11 \%)$ patients. All nodal failures were in the ipsilateral supraclavicular region (10). The same team subsequently published another prospective phase II study, this time the pre-chemotherapy primary tumour and nodal volumes (no ENI) was defined on 18FDG positron-emission tomography/computed tomography (PET-CT). They reported only two isolated lymph node recurrences out of the 60 patients (crude rate of $3 \%$ ) studied. The authors concluded that RT limited to the involved lymph nodes is a safe treatment, provided that a PET/CT scan is used for target volume definition (11). A further retrospective study using the same strategy reported only one nodal failure among 60 (crude rate of $2 \%$ ) LS-SCLC (12).

The second question on RT target volume in LSSCLC is related to the need to include the pre or the post chemotherapy volume. In a retrospective study, no difference in outcomes was observed in LS-SCLC patients treated with thoracic RT fields that included the prechemotherapy or the post-chemotherapy primary tumour volumes (ENI in all patients) (13). Two randomized trials compared post-chemotherapy versus pre-chemotherapy volumes. The Southwest Oncology Group (SWOG) study, performed in the 1980s, included 198 LS-SCLC patients with stable disease or partial response after induction chemotherapy. They were randomized to receive RT either to the pre-chemotherapy or post-chemotherapy tumour volume. ENI was used in all patients. Baseline assessments 
were performed with chest $\mathrm{x}$-ray, bone scan, bone marrow aspiration/biopsy, and a CT scan of the abdomen. Induction chemotherapy consisted of MV-VAC (vincristine, methotrexate, VP-16, doxorubicin, and cyclophosphamide for 6 weeks). Treatment planning and response assessment were performed with chest X-rays (two dimensional RT, 2D-RT). After 2D-RT, patients received post-RT chemotherapy (VP-16 and cyclophosphamide for four cycles), and then reinduction chemotherapy (MV-VAC with dose reduction). Survival and pattern of failures were not different between both arms. An increase in severe toxicity (myelosuppression) was however reported for patients receiving RT larger pre-chemotherapy volumes (7).

The study of $\mathrm{Hu}$ et al. is the second randomized study in LS-CLC comparing irradiation to the prechemotherapy (control arm) and the post-chemotherapy (experimental arm) tumor volume after 2 cycles of induction chemotherapy. ENI was omitted in all patients. An interim analysis was published in $2012(\mathrm{n}=86)(8)$ and the final results were reported in $2019(\mathrm{n}=309)$ (9). Due to slow accrual (recruitment 2002-17), the study was prematurely closed. The initial target population was 504 patients and 309 were actually randomised. Some $(n=9)$ patients were included in the intent-to-treat analysis of overall survival (OS) only. Baseline assessment included brain CT or MRI, body CT and bone scintigraphy. PET/ CT was not mandatory and was performed in $19 \%$ of patients. After an interim analysis, some patients received supraclavicular fine-needle aspiration to confirm any suspected lymphadenopathy but results not reported. Chemotherapy consisted of standard etoposide and cisplatin for 4 to 6 cycles (mean $4.3 \pm 1.0$ ). In this study conformal 3D thoracic RT was administered concurrently with the third cycle and consisted of 1.5 Gy twice a day in 30 fractions over a 3-week period to a total dose of $45 \mathrm{~Gy}$, which is the international standard. However, evidence from clinical trials supports that thoracic RT should preferentially be initiated early (e.g., with the first or second cycle of chemotherapy) as it improves patients' outcomes $(4,14)$. Nonetheless in some situations it may be advantageous to obtain tumour shrinkage in order to reduce the risk of chemo-radiotherapy toxicity. In such cases starting RT with cycle 3 of chemotherapy may provide comparable results to starting with cycle 1 or 2 , although the data are more limited $(15,16)$. Almost half of participants $(n=149 / 300$; $49.7 \%$ ) received thoracic intensity-modulated RT (IMRT). The use of 4DCT for RT planning and cone beam CT for treatment verification was not reported. Patients who achieved complete response of tumour after the completion of chemoradiotherapy were offered prophylactic cranial irradiation $(\mathrm{n}=195 / 300 ; 65 \%)$. Clinical target volumes (CTVs) included the pre- or post-chemotherapy primary tumour volume (control and experimental arm respectively) with a margin of $0.8 \mathrm{~cm}$ and the pre-chemotherapy nodal volume. The planning target volumes (PTVs) included the CTVs with a margin of $1.0-1.5 \mathrm{~cm}$. The principal objective of this trial was 3-year local/regional progression-free probability non-inferiority of the experimental arm (postchemotherapy primary tumour volume) compared with the control arm (pre-chemotherapy primary tumour volume).

Local/regional failure $(\mathrm{P}=0.77)$ was observed among 52 patients (34.2\%) in the study arm and $46(31.1 \%)$ in the control arm (median follow-up of 19.6 months, range, 0.7165.0 months). Among these, isolated out-field lymph node failure developed in $4 / 152$ (crude rate of $2.6 \%$ ) in the postchemotherapy experimental arm and $6 / 148$ patients (crude rate of $4.1 \%$ ) in the control arm, with 7 failures located in the supraclavicular regions and 3 located in contralateral hila. No out-field recurrence in the mediastinal lymph nodes was observed. There was no significant difference in 3-year local/regional progression-free and OS rates (65.5\% and $58.2 \%$ and in the control and experimental arms respectively; $\mathrm{P}=0.44$ ), and the absolute difference was $-7.3 \%$ (95\% CI, $-18.2 \%, 3.7 \%$ ). However as pointed out by the authors, the study was underpowered. Furthermore, the lower bound of the $95 \%$ confidence interval did exceed the lower bound of $-10 \%$, which was the defined study non-inferiority margin. It is therefore possible that the experimental arm could be inferior to the control arm. Rates of acute grade 3 esophagitis $(\mathrm{P}=0.01)$ and late grade 2-3 pulmonary fibrosis $(\mathrm{P}=0.01)$ were higher in the control arm than in the experimental arm. The authors should be commended for a very thorough dosimetric analysis showed that IMRT delivered more incidental doses to the noninvolved lymph node region than with 3D-RT. It is possible that this incidental dose could play a role in eliminating the microscopically invaded lymphadenopathy (9).

The study by $\mathrm{Hu}$ et al. is the only randomized study to date that has compared irradiation of the pre-chemotherapy and post chemotherapy primary tumour volume after induction chemotherapy, with omission of ENI. This study confirms findings from other studies that have examined the concept of involved field RT. Isolated out-field lymph node failure rates (crude rate of $2.6 \%$ ) was comparable to those described in studies including PET/CT for target definition $(11,12)$. The randomized CONVERT study 
comparing twice-daily to once-daily radiotherapy in LSSCLC reported good outcome in patients treated without ENI (survival at 5 years $34 \%$ and $31 \%$ respectively) (3). Approximately half of the patients were staged with PET/ CT. The risk of locoregional relapse was $14 \%$ for stage I and II and $17 \%$ for stage III SCLC (17). A pattern of relapse analysis based on the CONVERT data is under way. Finally, a recent study in the NSCLC setting has also confirmed that omission of ENI should be considered standard of care (18).

This study also included recent imaging and modern RT techniques (3D or IMRT). However, data on IMRT is limited in the SCLC setting. A retrospective study found comparable outcomes but fewer percutaneous feeding tube insertions (5\% vs. 17\%) in SCLC patients receiving IMRT $(\mathrm{n}=104)$ as compared to those receiving 3D-RT $(\mathrm{n}=119)(19)$. The study by $\mathrm{Hu}$ et al. reported lower rates of severe oesophageal toxicity compared to the recently published CONVERT study (10.7\% vs. $19.4 \%$ in CONVERT). This is possibly explained by a larger proportion of patients treated with IMRT (50\% in Hu vs. $17.4 \%$ in CONVERT) delivery (3).

In conclusion, in the LS-SCLC setting, treatment volumes should include the post-chemotherapy primary tumour volume and nodal regions involved at the time of initial diagnosis, omitting ENI (20). PET/CT is mandatory for RT planning. Pathologically confirmed lymph nodes on endoscopic ultrasound with or without fine needle aspiration techniques/mediastinoscopy, if available, should also be performed. Smaller fields lead to reduced toxicity from combined modality therapy without jeopardizing local control rates $(7,11,21,22)$.

\section{Acknowledgments}

Funding: Prof Corinne Faivre-Finn was supported by NIHR Manchester Biomedical Research Centre.

\section{Footnote}

Conflicts of Interest: Both authors have completed the ICMJE uniform disclosure form (available at http://dx.doi. org/10.21037/atm.2020.04.45). CFF reports grants from Astra Zeneca, grants from Elekta, outside the submitted work. AL has no conflicts of interest to declare.

Ethical Statement: The authors are accountable for all aspects of the work in ensuring that questions related to the accuracy or integrity of any part of the work are appropriately investigated and resolved.

Open Access Statement: This is an Open Access article distributed in accordance with the Creative Commons Attribution-NonCommercial-NoDerivs 4.0 International License (CC BY-NC-ND 4.0), which permits the noncommercial replication and distribution of the article with the strict proviso that no changes or edits are made and the original work is properly cited (including links to both the formal publication through the relevant DOI and the license). See: https://creativecommons.org/licenses/by-nc-nd/4.0/.

\section{References}

1. Pignon JP, Arriagada R, Ihde DC, et al. A meta-analysis of thoracic radiotherapy for small-cell lung cancer. $\mathrm{N} \mathrm{Engl} \mathrm{J}$ Med 1992;327:1618-24.

2. Roswit B, Patno ME, Rapp R, et al. The survival of patients with inoperable lung cancer: a large-scale randomized study of radiation therapy versus placebo. Radiology 1968;90:688-97.

3. Faivre-Finn C, Snee M, Ashcroft L, et al. Concurrent once-daily versus twice-daily chemoradiotherapy in patients with limited-stage small-cell lung cancer (CONVERT): an open-label, phase 3, randomised, superiority trial. Lancet Oncol 2017;18:1116-25.

4. De Ruysscher D, Pijls-Johannesma M, Bentzen SM, et al. Time Between the First Day of Chemotherapy and the Last Day of Chest Radiation Is the Most Important Predictor of Survival in Limited-Disease Small-Cell Lung Cancer. J Clin Oncol 2006;24:1057-63.

5. Xia B, Chen GY, Cai XW, et al. Is involved-field radiotherapy based on $\mathrm{CT}$ safe for patients with limited-stage small-cell lung cancer? Radiother Oncol 2012;102:258-62.

6. Videtic GM, Belderbos JS, Spring Kong FM, et al. Report from the International Atomic Energy Agency (IAEA) consultants' meeting on elective nodal irradiation in lung cancer: small-cell lung cancer (SCLC). Int J Radiat Oncol Biol Phys 2008;72:327-34.

7. Kies MS, Mira JG, Crowley JJ, et al. Multimodal therapy for limited small-cell lung cancer: a randomized study of induction combination chemotherapy with or without thoracic radiation in complete responders; and with widefield versus reduced-field radiation in partial responders: a Southwest Oncology Group Study. J Clin Oncol 1987;5:592. 
8. Hu X, Bao Y, Zhang L, et al. Omitting elective nodal irradiation and irradiating postinduction versus preinduction chemotherapy tumor extent for limited-stage small cell lung cancer: interim analysis of a prospective randomized noninferiority trial. Cancer 2012;118:278-87.

9. Hu X, Bao Y, Xu Y, et al. Final report of a prospective randomized study on thoracic radiotherapy target volume for limited-stage small cell lung cancer with radiation dosimetric analyses. Cancer 2020;126:840-9.

10. De Ruysscher D, Bremer RH, Koppe F, et al. Omission of elective node irradiation on basis of CT-scans in patients with limited disease small cell lung cancer: a phase II trial. Radiother Oncol 2006;80:307.

11. van Loon J, De Ruysscher D, Wanders R, et al. Selective nodal irradiation on basis of (18)FDG-PET scans in limited-disease small-cell lung cancer: a prospective study. Int J Radiat Oncol Biol Phys 2010;77:329.

12. Shirvani SM, Komaki R, Heymach JV, et al. Positron emission tomography/computed tomography-guided intensity-modulated radiotherapy for limited-stage small-cell lung cancer. Int J Radiat Oncol Biol Phys 2012;82:e91-7.

13. Liengswangwong V, Bonner JA, Shaw EG, et al. Limitedstage small-cell lung cancer: patterns of intrathoracic recurrence and the implications for thoracic radiotherapy. J Clin Oncol 1994;12:496.

14. De Ruysscher D, Lueza B, Le Péchoux C, et al. Impact of thoracic radiotherapy timing in limited-stage small-cell lung cancer: usefulness of the individual patient data metaanalysis. Ann Oncol 2016;27:1818-28.

15. Skarlos DV, Samantas E, Briassoulis E, et al. Randomized comparison of early versus late hyperfractionated thoracic

Cite this article as: Levy A, Faivre-Finn C. Radiotherapy tumor volume for limited-stage small cell lung cancer: less is more. Ann Transl Med 2020;8(17):1114. doi: 10.21037/ atm.2020.04.45
637 irradiation concurrently with chemotherapy in limited disease small-cell lung cancer: a randomized phase II study 638 of the Hellenic Cooperative Oncology Group (HeCOG). Ann Oncol 2001;12:1231-8.

16. Sun JM, Ahn YC, Choi EK, et al. Phase III trial of concurrent thoracic radiotherapy with either first- or third-cycle 640 chemotherapy for limited-disease smallcell lung cancer. Ann Oncol 2013;24:2088-92.

17. Salem A, Mistry H, Hatton M, et al. Association of Chemoradiotherapy With Outcomes Among Patients With Stage I to II vs Stage III Small Cell Lung Cancer: Secondary Analysis of a Randomized Clinical Trial. JAMA Oncol 2019;5:e185335.

18. Nestle U, Schimek-Jasch T, Kremp S, et al. Imagingbased target volume reduction in chemoradiotherapy for locally advanced non-small cell lung cancer (PET-Plan): a prospective randomised international multicentre trial. Lancet Oncol 2020. [Epub ahead of print].

19. Shirvani SM, Juloori A, Allen PK, et al. Comparison of 2 common radiation therapy techniques for definitive treatment of small cell lung cancer. Int J Radiat Oncol Biol Phys 2013;87:139-47.

20. Laurans M, Botticella A, Moukasse Y, et al. Lung cancer and elective nodal irradiation: A solved issue? Cancer/ Radiothérapie 2019;23:701-7.

21. Bonner JA, Sloan JA, Shanahan TG, et al. Phase III comparison of twice-daily split-course irradiation versus once-daily irradiation for patients with limited stage smallcell lung carcinoma. J Clin Oncol 1999;17:2681.

22. Chargari C, Magne N, Guy JB, et al. Optimize and refine therapeutic index in radiation therapy: Overview of a century. Cancer Treat Rev 2016;45:58-67. 